\title{
Use of Natural Deep Eutectic Solvents for Polymerization and Polymer Reactions
}

\author{
Analía V. Gómez, ${ }^{a, b}$ Atanu Biswas, ${ }^{\circledR *, c}$ Carmen C. Tadini, ${ }^{a, b}$ Roselayne F. Furtado, ${ }^{d}$ \\ Carlucio R. Alves ${ }^{e}$ and Huai N. Cheng*ff \\ ${ }^{a}$ Departamento de Engenharia Química, Escola Politécnica, Universidade de São Paulo, \\ 05508-010 São Paulo-SP, Brazil \\ ${ }^{b}$ Centro de Pesquisa em Alimento (FoRC), Núcleo de Apoio à Pesquisa em Alimentos e Nutrição (NAPAN), \\ Universidade de São Paulo, 05508-010 São Paulo-SP, Brazil \\ 'USDA Agricultural Research Service, National Center for Agricultural Utilization Research, \\ 1815 North University Street, 61604 Peoria, IL, USA \\ ${ }^{d}$ Embrapa Agroindústria Tropical, Rua Dra. Sara Mesquita, 2270, 60511-110 Fortaleza-CE, Brazil \\ ${ }^{e}$ Departamento de Química, Universidade Estadual do Ceará, Av. Dr. Silas Munguba, \\ 1700, 60740-903 Fortaleza-CE, Brazil \\ ${ }^{f}$ USDA Agricultural Research Service, Southern Regional Research Center, \\ 1100 Robert E. Lee Blvd., 70124 New Orleans, LA, USA
}

\begin{abstract}
Green chemistry is a key opportunity in chemistry and chemical engineering today because it can potentially preserve the environment and human health. It entails the choice of natural biodegradable raw materials and solvents, environmentally acceptable processes, and minimal use of non-hazardous chemicals. Previously, deep eutectic solvents (DES) have found many applications in organic, analytical, and polymer chemistry. The recent discovery of natural deep eutectic solvents (NADES), where many plant-abundant primary metabolites have been found to change their state from solid to liquid at certain temperatures when mixed in a proper ratio, should accelerate their use as replacements for common organic solvents that exhibit inherent toxicity and high volatility. In this work, we have reviewed the application of NADES as green, sustainable solvents in processes that involve polymerizations and polymer reactions. It is clear that many applications have already been explored. Undoubtedly more progress will be made in the future, and NADES will become more commonly used in polymer-related processes.
\end{abstract}

Keywords: natural deep eutectic solvents, polymer hydrolysis, polymer modifications, polymer reactions, polymerization

\section{Introduction}

Because of increasing environmental and safety concerns over the production and disposal of polymeric materials, there have been a lot of research and development (R\&D) and commercial activities involving bio-based materials from agricultural feedstocks. ${ }^{1,2}$ Sustainable technologies are also needed to replace polymer products made from petroleum-based feedstock. In both R\&D and production, the use of appropriate solvents is often critical. However, most chemical reactions cannot be conducted in water, and many organic solvents pose health and safety

*e-mail: atanu.biswas@ars.usda.gov; hn.cheng@ ars.usda.gov hazards. The introduction of ionic liquids (ILs) as solvents was considered an improvement; ${ }^{3-5}$ yet many of them are expensive and are not really eco-friendly. ${ }^{6} \mathrm{~A}$ breakthrough has appeared in the form of deep eutectic solvents (DES). ${ }^{7-13}$ These constitute a new class of solvents obtained by mixing two or more substances, which form eutectic mixtures with melting points much lower than that of the individual components. Like ionic liquids, DES solvents have many attractive physicochemical properties, such as chemical and thermal stability, non-flammability, high electrical conductivity, and solubilization of a number of organic compounds. Thus, these materials have the potential of replacing conventional organic solvents for polymerization and polymer reactions. More recently, natural deep eutectic 
solvents (NADES), such as mixtures of choline chloride/ urea, choline chloride/glycerol, and malic acid/glucose, have been found to be even more attractive because they comprise agro-based, natural, renewable components. ${ }^{14-20}$

The use of DES and NADES in polymer science is fairly recent, but quite a few papers have already been published that relate to polymer chemistry. Previously, three review articles have appeared on the use of DES for selected polymerization reactions..$^{12,13,21}$ Two related reviews deal with biocatalyses and biotransformations ${ }^{22,23}$ and one deals with biomass utilization ${ }^{24}$ in the presence of DES. In this work, we have provided an updated review of polymerization and polymer reactions using NADES, with some related papers on DES included for convenience and future reference. It is the authors' hope that this work will stimulate further interest of this class of eco-friendly solvents among polymer scientists.

\section{General Description of NADES}

NADES constitute a new generation of deep eutectic solvents, introduced by Choi et al. ${ }^{14}$ A NADES solvent is defined as a combination of two or three natural, renewable, biodegradable and inexpensive natural substances which are capable of self-association, often through specific interactions, to form a eutectic mixture. These specific interactions are responsible for the decrease of the melting point of the mixture. The melting point of the eutectic mixture is generally lower than those of each individual component; in general, the NADES of interest are liquids from room temperature to $100{ }^{\circ} \mathrm{C}$.

In past reviews, DES are sometimes considered to be mixtures of a salt and hydrogen-bond donor, ${ }^{9,10}$ or mixtures of hydrogen-bond acceptor (HBA), such as a quaternary salt, and a hydrogen-bond donor (HBD), such as an organic acid, carbohydrate, amine, or polyol. ${ }^{12}$ When an HBD is used to form a eutectic mixture, charge delocalization is presumed to occur through hydrogen-bond formation between the HBA and the HBD molecules. As we surveyed the many NADES reported, it is clear that hydrogen bonding is not the only mechanism possible. We have grouped the common NADES into three types (Table 1) depending on the interactions between the components: (i) ionic, (ii) polar, and (iii) hydrogen bonding. The major difference between NADES and DES is the use of natural components in the former case, but the nature of the interactions is similar. Sometimes a clear distinction between NADES and DES cannot easily be made; for example, acetic acid, succinic acid, itaconic acid, levulinic acid, ethanol, ethylene glycol, 1,2-propanediol and others can be made from both petroleum and bio-based materials and processes. Note also that the ionic interactions in DES are similar to the ionic interactions in ionic liquids, although the optimal molecules used for ILs and DES may be different. For convenience, some common NADES solvent systems are given in Table 2; their chemical structures are given in the Supplementary Information.

Compared with IL, the process of making NADES is relatively simple, and the eutectic mixture can often be obtained in high purity and low cost. A typical preparative method consists of mixing components in a proper ratio under heating until a homogenous liquid is obtained. NADES generally exhibit properties such as low vapor pressure, low toxicity, water compatibility, biodegradability and non-flammability. All these properties make NADES viable alternatives to traditional organic solvents, which may have varying degrees of toxicity or volatility. Since NADES are easily prepared from relatively pure components, purification is usually not necessary, and often a $100 \%$ atom utilization rate is obtained.

NADES have been employed in a wide range of applications, including electrochemistry, ${ }^{25-28}$ bioenergy, ${ }^{29-32}$ enzyme-catalyzed reactions, ${ }^{33-36} \mathrm{CO}_{2}$ adsorption, ${ }^{37-39}$ biomass processing, ${ }^{24,40,41}$ and separation and extraction of target compounds from natural products. ${ }^{42-48}$ In the next three sections, we shall provide a review of the application of NADES in processes that involve polymerizations and polymer reactions. As indicated above, sometimes the distinction between NADES and (non-natural) DES is not straightforward, and we have included some non-natural DES in the following review.

\section{Polymerization}

In polymer product development, polymerization is often needed to produce new or improved polymers. Whereas some polymers can be made neat or in water, the majority of polymers are made in organic solvents. Thus, eco-friendly solvents like NADES or DES can be useful here.

\subsection{Addition polymers}

In an approach used by Mukesh et al. ${ }^{49}$ a novel natural deep eutectic solvent was prepared by the endothermic complexation of choline chloride and orcinol at room temperature. Among $N$-isopropyl acrylamide (NIPAM), vinyl acetate (VA) and 2-hydroxyethyl methacrylate (HEMA), only HEMA was found to be self-polymerized in the above solvent at room temperature at optimized concentrations resulting in the formation of a highly stretchable gel. 
Table 1. Types components, and examples of common natural deep eutectic solvents (NADES) and some non-NADES components

\begin{tabular}{l}
\hline NADES components \\
\hline \\
$\begin{array}{l}\text { (1) organic cations + carboxylic acids } \\
\text { (2) amino acid + carboxylic acid }\end{array}$ \\
Ionic $\quad \begin{array}{c}\text { (3) metal carboxylate salt + carboxylic } \\
\text { acid }\end{array}$ \\
metal salts \\
\end{tabular}

$\begin{array}{ll} & \\ \text { (1) organic cation + sugar } & \text { (1a) organic cation + hydroxy cpd } \\ \text { (2) organic cation + urea } & \\ \text { (3) amino acid + sugar } & \end{array}$

(5) organic cation + amide (6) inorganic metal salt + sugars

(1) carboxylic acid + carboxylic acid

(2) carboxylic acid + sugar

Hydrogen bonding

(3) sugar + sugar

(4) urea + sugar (2a) carboxylic acid + hydroxy cpd (3a) polyol + hydroxy cpd (4a) urea + hydroxy cpd carboxylic acids:

(i) lactic acid, maleic acid, acetic acid, oxalic acid, malonic acid, succinic acid, malic acid, citric acid, aconitic acid, tartaric acid, phytic acid, itaconic acid, caffeic acid, $p$-coumaric acid, cinnamic acid, gallic acid, suberic acid (ii) acrylic acid, methacrylic acid, $p$-toluenesulfonic acid, 2-hydroxybenzoic acid, phenylacetic acid

acid salts:

glutamic acid salt, sodium phytate

sugars:

erythritol, xylitol, adonitol, ribitol, sorbitol, xylose, rhamnose, glucose, fructose, sorbose, mannose, galactose, sucrose, trehalose, maltose, raffinose, inositol

hydroxy compounds:

glycerol, ethylene glycol, 1,2-propanediol, phenol, triethylene glycol, $o$-cresol,

2,3-xylenol, isosorbide, 1,4-butanediol, resorcinol

amino acids:

betaine, proline, alanine, serine

ureas:

urea, 1-methylurea, 1,3-dimethylurea, ethylene urea, thiourea, propylene urea

amides:

acrylamide, acetamide, trifluoroacetamide, benzamide

inorganic metal salts:

$\mathrm{SnCl}_{2}, \mathrm{ZnCl}_{2}, \mathrm{CrCl}_{3}, \mathrm{ZnClO}_{4}, \mathrm{MgClO}_{4}$

1a, 2a, 3a, 4a: similar to item 1, 2, 3 and 4, respectively, but not "natural".

Bednarz et al..$^{50}$ devised new methods of preparation of hydrogels and xerogels from itaconic acid in DES involving choline chloride. Moreover, a surfactant-free method of creating macroporous poly(itaconic-co-bisacrylamide) by phase separation polymerization in binary mixture of the DES and poly(ethylene glycol) was shown.

In several papers, Mota-Morales et al..$^{51-53}$ carried out frontal polymerization using DES. In the first paper, ${ }^{51}$ they demonstrated superior performance for the frontal polymerizations using mixtures of acrylic acid or methacrylic acid and choline chloride, relative to regular organic solvents and even ionic liquids. They also showed full recovery of choline chloride after polymerization. In a second paper, ${ }^{52}$ they extended their work to acrylic acid and acrylamide and also incorporated an active filler into the polymeric matrix. In yet another paper, ${ }^{53}$ they synthesized macroporous poly(acrylic acid)-carbon nanotube composites by frontal polymerization in DES. They have recently written a review article on this topic, ${ }^{21}$ where more detailed information on this and related work can be found.

Wang et al..$^{54}$ used several DES for atom transfer radical polymerization (ATRP) of methyl methacrylate with $\mathrm{FeBr}_{2}$ 
Table 2. Commonly used combinations of natural deep eutectic solvents

\begin{tabular}{|c|c|}
\hline NADES components & Molar ratio \\
\hline Choline chloride:urea & $1: 2$ \\
\hline Choline chloride:oxalic acid & $1: 1$ \\
\hline Choline chloride:malonic acid & $1: 1$ \\
\hline Choline chloride:succinic acid & $1: 1$ \\
\hline Choline chloride:citric acid & $2: 1,1: 1,1: 2,1: 3$ \\
\hline Choline chloride:lactic acid & $1: 1$ \\
\hline Choline chloride:malic acid & $1: 1,1: 2,1: 3$ \\
\hline Choline chloride:malic acid:water & $1: 1: 2$ \\
\hline Choline chloride:glycerol & $1: 1,1: 2,1: 3,1: 4$ \\
\hline Choline chloride:glycerol:water & $1: 2: 1$ \\
\hline Choline chloride:glucose & $1: 1$ \\
\hline Choline chloride:glucose:water & $1: 1: 1,5: 2: 5$ \\
\hline Choline chloride:xylitol & $1: 1$ \\
\hline Choline chloride:xylitol:water & $1: 1: 2,1: 2: 3$ \\
\hline Betaine:sucrose & $1: 1,2: 1,4: 1$ \\
\hline Betaine:citric acid & $1: 1$ \\
\hline Betaine:citric acid:water & $1: 1: 5$ \\
\hline Citric acid:proline & $1: 1,2: 1,3: 1$ \\
\hline Citric acid: $\beta$-alanine:water & $1: 1: 3$ \\
\hline Citric acid:glucose & $2: 1,1: 1$ \\
\hline Citric acid:glucose:water & $1: 1: 5$ \\
\hline Lactic acid:glucose & $5: 1$ \\
\hline Lactic acid:glucose:water & $5: 1: 3$ \\
\hline Lactic acid: $\beta$-alanine & $1: 1$ \\
\hline Lactic acid: $\beta$-alanine:water & $1: 1: 3$ \\
\hline Lactic acid:proline & $1: 1$ \\
\hline Malic acid:glucose & $1: 1,1: 2$ \\
\hline Malic acid:proline & $1: 1$ \\
\hline Malic acid:sorbitol & $1: 1$ \\
\hline Malic acid:sorbitol:water & $1: 1: 3$ \\
\hline Glucose:fructose & $1: 1$ \\
\hline Glucose:sucrose & $1: 1$ \\
\hline
\end{tabular}

in the absence of any additional ligands. They classified DES in three types: amide compounds (type I), inorganic salts (type II) and quaternary ammonium salts (type III). Owing to the nature of DES, the system developed was much more environmentally benign and relatively cheap in comparison with most conventional iron-catalyzed ATRP systems reported. Moreover, the DES-tuned ATRP could be a great opportunity to utilize environmental friendly media and could drastically reduce the high costs caused by common ligands. In a related work, ATRP of methyl methacrylate in the presence of glycerol/1,3-dimethyl2-imidazolinone was reported by Tian et al. ${ }^{55}$
In another paper, Mendonça et al..$^{56}$ used $\mathrm{Na}_{2} \mathrm{~S}_{2} \mathrm{O}_{4}$ and choline chloride/urea as supplemental activator and reducing agent ATRP for several hydrophilic monomers. The resulting polymers exhibited low polydispersity. Block copolymers were also prepared.

A different study ${ }^{57}$ entailed the enzyme-mediated free radical polymerization of acrylamide in choline chloride/ urea and choline chloride/glycerol. There was a decrease in the activity of the enzyme (horseradish peroxidase), but acrylamide could be fully converted to polymer with similar molecular weight as aqueous polymerization. An advantage of NADES was the low temperature $\left(4{ }^{\circ} \mathrm{C}\right)$ that could be used for polymerization, whereas no polymer was found for the polymerization in water.

In a paper by Fernandes et al.,$^{58}$ biodegradable deep-eutectic mixtures were used as electrolytes for the electromechanical synthesis of conducting polymers. The NADES consisted of a 1:2 mixture of choline chloride and ethylene glycol. The polymer used as a model was polyaniline. Cyclic voltammetry was employed for polymerization and for the characterization of the growth of the polymer. The polyanilines thus prepared exhibited nanoparticulated morphology and high reversibility to doping/dedoping, which evidenced fast charge transport across the films. Excellent conductivities higher than $50 \mathrm{~S} \mathrm{~cm}^{-1}$ were found using this approach.

Park and $\mathrm{Lee}^{59}$ employed DES as an alternative reaction media in $\mathrm{FeCl}_{3}$-catalyzed oxidative polymerization of 3-octylthiophene (3-OT). The synthesis of poly(3-OT) using choline chloride:urea $(\mathrm{ChCl}: \mathrm{U})$ or choline chloride:urea:thiourea (ChCl:U:TU) reached a yield of $100 \%$ within 2 and $3 \mathrm{~h}$ at $50{ }^{\circ} \mathrm{C}$, respectively. In the case of $\mathrm{ChCl}: \mathrm{U}$, the yield became higher than that of conventional polymerization in chloroform after $4 \mathrm{~h}$. These authors found that the DES also had the potential of replacing ILs and conventional volatile organic solvents for the development of environmentally benign industrial processes with respect to organic light-emitting diodes (OLEDs), optical sensors, and luminescent devices.

Hosu et al. ${ }^{60}$ utilized electropolymerization in DES to prepare poly(methylene blue) (PMB) polymers with different nanostructured morphologies. PMB films were synthesized on glassy carbon electrodes (GCE) by potential cycling from a mixture of $90 \%$ ethaline (choline chloride:ethylene glycol) and $10 \%$ aqueous solution with different ionic composition, i.e., $\mathrm{Na}^{+}, \mathrm{SO}_{4}^{2-}, \mathrm{ClO}^{4}, \mathrm{NO}_{3}^{-}, \mathrm{Cl}$. $\mathrm{PMB}$ polymer films with unique nanostructures have been successfully synthesized in ethaline plus $10 \% \mathrm{v} / \mathrm{v}$ aqueous solution of $0.1 \mathrm{M} \mathrm{NaOH}$ and $0.1 \mathrm{M} \mathrm{HClO}_{4}$ in the final DES optimized mixture. All PMB films obtained from DES $\left(\mathrm{PMB}_{\mathrm{DES}}\right)$ exhibited higher redox currents and a significantly lower charge transfer 
resistance than $\mathrm{PMB}$ obtained in aqueous media $\left(\mathrm{PMB}_{\mathrm{aq}}\right)$. Moreover, GCE modified with $\mathrm{PMB}_{\mathrm{DES}}$ obtained at different scan rates, from 100 to $500 \mathrm{mV} \mathrm{s}^{-1}$, revealed their superior sensing performance compared to $\mathrm{GCE} / \mathrm{PMB}_{\mathrm{aq}}$, and that $\mathrm{PMB}_{\mathrm{DES}}$ obtained at $150 \mathrm{mV} \mathrm{s}{ }^{-1}$ scan rate is the most suitable for this purpose.

\subsection{Condensation polymers}

Garcia-Arguelles et al. ${ }^{61}$ showed that DES could serve not only as an efficient solvent for polymerization but also as an efficient carrier of active principal ingredients. Thus, they successfully prepared biodegradable poly(octanediolco-citrate) polyesters using a DES solvent including quaternary ammonium or phosphonium salts and octanediol. In the resulting polymers, the presence of quaternary ions (i.e., choline chloride, tetraethylammonium bromide, hexadecyltrimethylammonium bromide, and methyltriphenylphosphonium bromide) inhibited bacterial growth in the early post-implantation steps, as tested in cultures of Escherichia coli on solid agar plates. Some of these antibacterial, biocompatible, and biodegradable polyesters might be potential candidates for the preparation of antimicrobial wound dressings. In a similar approach, Serrano et al. ${ }^{62}$ synthesized novel poly(octanediolco-citrate) elastomers containing high loading of lidocaine at temperatures below $100^{\circ} \mathrm{C}$ by means of deep eutectic mixtures of 1,8-octanediol and lidocaine. The preservation of lidocaine integrity resulted in high-capacity drug-eluting elastomers.

Gómez-Patiño et al..$^{63}$ carried out the polymerization of 10,16-dihydroxyhexadecanoic acid (main monomer of the tomato cuticle obtained from agro-residual wastes) using choline chloride $+\mathrm{ZnCl}_{2}$ as catalyst at three different temperatures $\left(80,90\right.$, and $\left.100{ }^{\circ} \mathrm{C}\right)$. The resulting polyesters obtained under these conditions were insoluble in most of the organic solvents and showed different physicochemical properties. At $80^{\circ} \mathrm{C}$, the products were obtained as powders, but at higher temperature, they were found as viscous liquids.

Two papers ${ }^{64,65}$ dealt with the curing process of epoxy resin with DES serving as solvents and catalysts. The eutectic mixture of choline chloride and urea was shown to initiate the polymerization of diglycidyl ether of bisphenol A (DGEBA) to a low molecular weight resin in the absence of a hardener. ${ }^{64}$ Fourier transform infrared spectroscopy (FTIR) and differential scanning calorimetry (DSC) were used to study the reaction kinetics. In a different approach, a mixture composed of choline chloride and $\mathrm{ZnCl}_{2}$ or $\mathrm{SnCl}_{2}$ was studied as a cationic catalyst for epoxy curing, using rheometry, DSC, and FTIR techniques. ${ }^{65}$ A curing mechanism was reported, together with the solvent effect and various polymer properties.
A series of papers by Gutiérrez and co-workers ${ }^{66-68}$ were published on resorcinol-formaldehyde (RF) resins made in the presence of DES. In the first paper, ${ }^{66}$ they polymerized RF resins in choline chloride-ethylene glycol. Carbonization of the resulting RF gels resulted in the formation of monolithic carbons with good conversion rates. Incorporation of carbon nanotubes (CNTs) was possible by adding CNTs in the DES during the preparation of the RF gels. In the second paper, ${ }^{67}$ they made DES with choline chloride, resorcinol (and urea) and prepared RF resin directly in this DES. In the third paper, ${ }^{68}$ they used a DES with resorcinol, choline chloride (0.928 g), and glycerol (0.612 g), added phosphoric acid, and formaldehyde. The resulting resin was carbonized to form phosphate-functionalized carbon monoliths.

In a related paper, Chen et al..$^{69}$ used choline chloride and urea to produce phenol-formaldehyde resin in a two-stage synthesis. The product was subjected to ambient drying and thermal treatment at $800{ }^{\circ} \mathrm{C}$ in nitrogen to generate carbon xerogels that exhibited a hierarchical porous structure. The xerogel contained nitrogen (from urea) at about 5-9\%, which might be desirable for $\mathrm{CO}_{2}$ capture.

\section{Polymer Reactions}

\subsection{Modifications of synthetic polymers}

Two papers were reported on polymer reactions involving DES and poly(ethylene terephthalate) (PET). In one report, ${ }^{70}$ rapid hydrophilic modification of poly(ethylene terephthalate) (PET) fabric was carried out by deep eutectic ethylene glycol-choline chloride mixture under microwave irradiation. Alkali concentration and microwave irradiation time were found to be critical factors in determining surface characteristics of PET. The addition of merely $0.5 \%$ sodium hydroxide to the treatment drastically changed the fiber surface from hydrophobic to highly hydrophilic.

Another report ${ }^{71}$ used urea and $\mathrm{ZnCl}_{2}$ together with ethylene glycol to degrade PET. With the DES, the degradation time was much shortened with a minimum number of degradation products. The reaction conditions were mild, and the reaction time minimized through optimization of reaction parameters. The high catalytic activity of DES was attributed to the synergetic catalysis of hydrogen bonds and coordination bonds formed between DES catalyst and ethylene glycol.

\subsection{Modifications involving polysaccharides and biomass}

Three papers dealt with reactions of polysaccharides..$^{72-74}$ In a promising study, ${ }^{72}$ two types of NADES involving 
urea and glycine were screened as media for facilitating methylation of chitosan. The results indicated that NADES did mediate selective $N$-methylation in the absence of $\mathrm{NaOH}$, with no polymer scission, when compared with conventional synthesis of $N$-methylated chitosan. ${ }^{1} \mathrm{H}$ nuclear magnetic resonance (NMR) spectra confirmed selective $N$-methylation in case of products obtained using urea, while that obtained using glycine demonstrated some $O$-methylation. Another green method employed lipase to methylate chitosan; the reaction was successful with the lipase from Burkholderia species, but unsuccessful with Candida antarctica lipase. The paper also reported the use of dimethyl carbonate as a benign methylating agent.

A green, new, and relatively cheap approach was shown to be suitable for synthesizing a cellulose-based macro-initiator. ${ }^{74}$ When the amounts of cellulose and zincbased ionic liquid were fixed at $0.5 \mathrm{~g}$ and $18 \mathrm{~mL}$, respectively, the degree of substitution of the cellulose-based macroinitiator obtained was increased from 11.0 to $17.4 \%$ as the reaction temperature was increased from room temperature to $40{ }^{\circ} \mathrm{C}$. When the amount of cellulose was cut in half, a degree of substitution of $27.5 \%$ was achieved due to lower viscosity and better homogeneity of the reaction medium.

In a different reaction, ${ }^{73}$ choline chloride coated on silica-supported $\mathrm{AlCl}_{3}$ permitted the dehydration of carbohydrates in low boiling point organic solvents. The concept was based on the in situ formation of a deep eutectic liquid phase on the catalyst surface, thus facilitating the interaction between the solid catalyst and insoluble carbohydrate.

Biomass obtained from brown seaweed, Sargassum tenerrimum, was complexed with the deepeutectic choline chloride and $\mathrm{FeCl}_{3}$ mixture and converted to graphene nanosheets through pyrolysis at $700-900{ }^{\circ} \mathrm{C}$ under $95 \% \mathrm{~N}_{2}$ and $5 \% \mathrm{H}_{2}$ atmosphere. ${ }^{75}$ The nanosheets thus synthesized were tested for their electrocatalytic activity in the oxygen reduction reaction (ORR) in alkaline fuel cells. The results suggested that the functionalized graphene sheets could be a sustainable replacement for existing precious metal-based ORR catalysts.

A review ${ }^{24}$ was published on lignocellulosic biomass utilization and conversion, including extraction of phenolic compounds, delignification, conversion to furanic derivatives, and processing of biodiesel and other fuels.

\subsection{Hydrolysis of polymeric materials}

DES and NADES have been found to be particularly useful for the hydrolysis of agro-based polymeric materials. Thus, in one report, ${ }^{76}$ NADES were formed at elevated temperatures $\left(60-100{ }^{\circ} \mathrm{C}\right)$ by combining choline chloride with carboxylic acids (anhydrous oxalic acid, oxalic acid dihydrate, $p$-toluenesulfonic acid monohydrate, and levulinic acid) and then used to hydrolyze less ordered amorphous regions of cellulose. All the NADES treatments resulted in degradation of wood fibers into micro-sized fibers, and after mechanical disintegration, carbon nanocrystals (CNCs) were successfully obtained from choline chloride/oxalic acid dihydrate-treated fibers. No CNCs was observed with the combination of NADES with other organic acids. This acidic NADES method was more advantageous over previously reported CNC productions, because of milder processing conditions and easily obtainable and relatively inexpensive biodegradable solvents with low toxicity, relative to ionic liquids.

In another study, ${ }^{77}$ corncob residues were pretreated with three different DES systems: choline chloride/ glycerol, choline chloride/imidazole, and choline chloride/ urea. The pretreated biomass was subsequently subjected to enzymatic saccharification and found to have enhanced sugar levels. Choline chloride/imidazole was the most effective solvent tested and could be applied at a lower temperature $\left(80{ }^{\circ} \mathrm{C}\right)$ than that required to achieve similar results with choline chloride/glycerol $\left(150^{\circ} \mathrm{C}\right)$.

$\mathrm{Xu}$ et $a l .{ }^{78}$ developed an effective corn stover (CS) pretreatment method for biobutanol fermentation. Seven DES were synthesized and evaluated in the pretreatment of CS (choline chloride/urea, choline chloride/glycerol, choline chloride/formic acid, choline chloride/acetic acid, choline chloride/oxalic acid, choline chloride/malonic acid, choline chloride/citric acid). In particular, choline chloride/formic acid displayed excellent performance in the pretreatment of corn stover by removal of hemicellulose and lignin as confirmed by scanning electron microscopy (SEM), FTIR and X-ray diffraction (XRD) analysis. After optimization, glucose released from pretreated CS reached $17.0 \mathrm{~g} \mathrm{~L}^{-1}$ and yield of $99 \%$. The CS hydrolysate was successfully utilized in butanol fermentation by Clostridium saccharobutylicum DSM 13864, achieving butanol titer of $5.63 \mathrm{~g} \mathrm{~L}^{-1}$ with a yield of $0.17 \mathrm{~g} \mathrm{~g}^{-1}$ total sugar and productivity of $0.12 \mathrm{~g} \mathrm{~L}^{-1} \mathrm{~h}^{-1}$. The authors concluded that DES could be used as a promising and biocompatible pretreatment method for the conversion of lignocellulosic biomass into biofuel.

Gunny et al. ${ }^{79}$ studied the applicability of DES-cellulase system for lignocellulose hydrolysis from rice husk. The DES consisted of choline chloride and a hydrogen-bond donor molecule (glycerol, ethylene glycol, or malonic acid). Cellulase showed higher activity and stability where more than $90 \%$ of its original activity was retained in the presence of DES based on glycerol or ethylene glycol. In view of the higher glucose production and lower energy consumption as compared to the diluted alkali pretreatment method, 
the authors proposed that those DES could be regarded as potential solvents for lignocelluloses pretreatment.

Kumar et $a l .{ }^{80}$ used NADES for the pretreatment of lignocellulosic biomass rice straw and the separation of high-quality lignin and holocellulose in a single step. Two types of NADES reagents were prepared using lactic acid/betaine (LA-BE) and lactic acid/choline chloride (LACC) in several molar ratios. They found that LACC at molar ratio of 5:1 extracted the maximum amount of lignin $\left(68 \pm 4 \mathrm{mg} \mathrm{g}^{-1}\right)$ from the rice straw biomass, and subsequent enzymatic hydrolysis of the residual holocellulose enriched biomass showed maximum reducing sugars of $333 \pm 11 \mathrm{mg} \mathrm{g}^{-1}$ with a saccharification efficiency of $36.0 \pm 3.2 \%$ in $24 \mathrm{~h}$ at $10 \%$ solids loading.

\section{Assessments}

As documented in the rapidly growing literature, NADES possess many advantages. They are eco-friendly, biodegradable, non-toxic, and sustainable. They are easy to prepare, low in volatility and flammability, and chemically and thermally stable. The components of NADES are readily available, relatively inexpensive, and can be recycled if needed. Although most NADES can be made without water, water can be added in many cases to provide a wider range of applications.

For the situation of polymerization and polymer reactions, NADES have some specific advantages over organic solvents. First, most NADES consist of a combination of a cationic species and an anionic species; thus, the solvent has a higher electrical conductivity than most organic solvents. The high conductivity has been helpful in electrochemical synthesis of conducting polymers ${ }^{58}$ oxidative polymerization of 3 -octylthiophene, ${ }^{59}$ and electropolymerization of poly(methylene blue). ${ }^{60}$ The high conductivity may also be conducive to microwaveassisted reactions and processes, although the current applications are relatively scarce. ${ }^{70,81}$ Secondly, the quaternary ammonium salts used in some NADES have been shown to impart antimicrobial properties to the resulting polyesters. ${ }^{61}$ Thirdly, the deep eutectic solvents can serve as catalysts in some cases, e.g., polymerization of DGEBA,${ }^{64}$ epoxy curing, ${ }^{65}$ degradation of poly(ethylene terephthalate), ${ }^{71}$ methylation of chitosan, ${ }^{72}$ and degradation of carbohydrates. ${ }^{73}$ Fourthly, NADES appear to be good solvents for reactions involving biomass. Thus, they have been used for the hydrolysis of the amorphous region in cellulose,${ }^{76}$ and pre-treatment of corn stover, ${ }^{78}$ rice straw, ${ }^{80}$ and rice husk ${ }^{79}$ for biomass conversion.

Despite the promise, the use of NADES has its limitations. First, there is only a limited understanding of the solubility mechanism so that one cannot predict the solubility of a given material (e.g., a monomer or a polymer) in a NADES solvent. Thus, a prospective user needs to try different NADES solvents to see if they can be beneficial for a polymer reaction. Secondly, many NADES solvents are viscous and difficult to handle; in some cases, this viscosity can be remedied by the addition of water. Thirdly, some of the components of NADES (e.g., in Table 2) are not chemically inert; therefore, care is needed to select the components not likely to participate in (or interfere with) the intended reaction. Finally, since NADES components have low volatility, it may be difficult sometimes to recover the solute from the NADES.

\section{Conclusions}

Polymers constitute a major category of industrial products with significant economic impact. The syntheses and production of polymers typically involve polymerization and polymer reactions. These processes are often carried out in organic solvents, which may incur some health or safety hazards. The discovery of deep eutectic solvents (DESs) has stirred up a lot of research interest in the chemistry community; this interest has been augmented by the recent addition of natural deep eutectic solvents (NADES), where many bio-based substances were found to change their state from solid to liquid at certain temperatures when mixed in a proper ratio. Because of their newness, these new solvents have not been extensively used in polymer science thus far, although quite a few papers have appeared.

In this review, the current use of NADES for polymerization and polymer reactions is reviewed. Although no specific emphasis has been placed on biomacromolecules, there have been several references to the use of NADES with respect to reactions of biomacromolecules (particularly hydrolysis), e.g., cellulose,${ }^{74,76}$ chitosan, ${ }^{72}$ other polysaccharides, ${ }^{73,77}$ biomass and lignocellusics, ${ }^{24,40,41,78-80}$ and lipid-related materials. ${ }^{29-31}$ This is probably a promising area for future research. In view of NADES as agro-based and environmentally friendly reaction media, we believe they have great promise as green solvents for polymer science. We hope this review may be informative to polymer scientists and help to accelerate the adoption of these solvents as replacements for organic solvents that may exhibit inherent toxicity, volatility, and/or flammability.

\section{Supplementary Information}

Mention of trade names or commercial products in this publication is solely for the purpose of providing 
specific information and does not imply recommendation or endorsement by the U.S. Department of Agriculture. USDA is an equal opportunity provider and employer.

Supplementary data are available free of charge at http://jbcs.sbq.org.br as PDF file.

\section{Acknowledgments}

This work was supported in part by São Paulo Research Foundation (FAPESP) under grants 2016/15783-9 and 2013/25496-4.

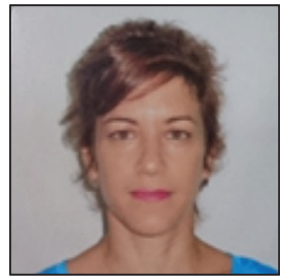

Dr Analía V. Gómez received her PhD in Biological Sciences from the University of La Plata and is currently conducting her postdoctoral research at University of São Paulo. She has been working in different areas of food science, such as cereals, fibers, starches and other polysaccharides, emulsifiers, and ionic liquids, covering topics that range from microbiology, shelf life, fruit ripening, and green chemistry. More recently, she has extracted soluble sugars from ripe bananas, testing different methodologies like solid-liquid extraction with mechanical agitation and the optimal use of ultrasound and microwave. In 2017, she served as a visiting scientist working with Dr Biswas at USDA National Center for Agricultural Utilization Resources in the USA.

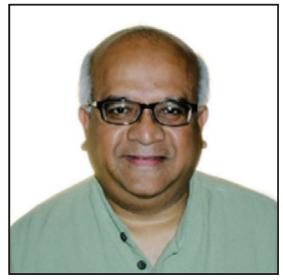

Dr Atanu Biswas received his PhD in Organic Chemistry from the University of Notre Dame and did postdoc work at the University of Virginia and Case Western Reserve University. He worked at Hercules Incorporated in Wilmington, Delaware in 1988-2003. Since 2003, he has been working in USDA National Center for Agricultural Utilization Resources in Peoria, Illinois. He is known for his pioneering polymer synthesis and modification work in development of bio-based plastics, coatings, films, hydrogels, absorbents, and bio-lubricants from agricultural products such as polysaccharides, vegetable oil, protein, edible beans, cotton, and agricultural byproducts by utilizing state-of-the-art technologies such as microwave, ionic liquid, and enzyme technologies. He has published over 100 papers and patent publications.

Dr Carmen C. Tadini received her PhD in Chemical Engineering from the University of São Paulo, Brazil and did postdoctoral work at Purdue University in USA. Since 1987, she has been working at University of São Paulo,

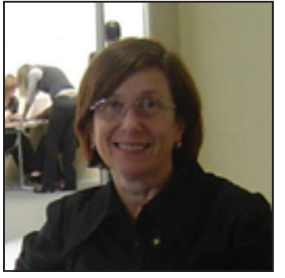

Main Campus, in SP, Brazil. She is known for her research using microwave technology for liquid food pasteurization, developing starch-based bio-nanocomposites for food packaging, and devising alternative routes to extract functional ingredients from fruits. Thus far, she has published over 70 papers, four patent publications, and three books.

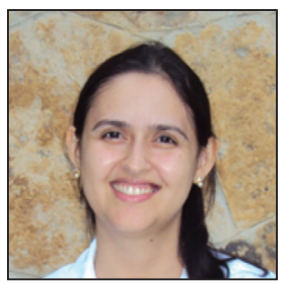

Dr Roselayne F. Furtado received her PhD in Biotechnology from the State University of Ceará in Brazil in 2011. She has worked at Embrapa Tropical Agroindustry since 2007. Her research covers a range of activities, including electrochemistry, biosensor technology, bioactive encapsulation, and biopolymers for food packaging. She has been serving as a leader of many research projects. Nowadays, she is also participating in the post-graduate program, collaborating with and mentoring graduate students. She has published over 30 papers. Two patents applications have also been submitted.

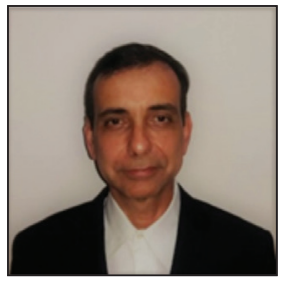

Dr Carlucio $R$. Alves received his PhD in Physical Chemistry from University of São Paulo (Brazil) and Autonomous University of Madrid (Spain) and performed his postdoctoral work at Embrapa Instrumentation (Brazil). Since 2001, he has been working in the State University of Ceará in Brazil. He is coordinator of the Post-graduate Program in Natural Sciences at the university. Over the years, he has been engaged in several research areas including electroanalytical chemistry, conductive polymers, natural product chemistry, bioremediation, and biosensor technology. He has published more than 60 articles and patent publications.

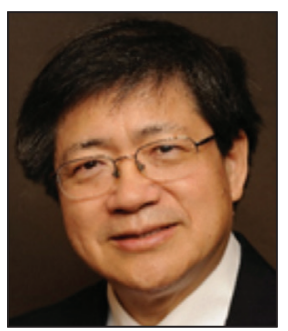

Dr Huai N. Cheng received his PhD in Physical Chemistry from the University of Illinois and carried out his postdoctoral work at Bell Labs. He worked at GAF Corporation and then at Hercules Incorporated. He joined USDA Southern Regional Research Center in New Orleans in 2009. Over the years, he has worked in a number of research areas, including green chemistry, natural renewable materials, enzyme biocatalysis, polymer reactions, polymer modeling and analysis, and NMR spectroscopy. His recent publications 
include adhesives from cottonseed protein, conversion of agricultural byproducts into value-added materials, and novel or improved reactions involving triglyceride oils and polysaccharides. He has published over 200 papers. He is also active professionally and has served in many capacities in the American Chemical Society at national, divisional, and local levels.

\section{References}

1. Cheng, H. N.; Gross, R. A.; Smith, P. B.; ACS Symposium Series, vol. 1192; American Chemical Society: Washington, DC, 2015.

2. Mathers, R. T.; Meier, M. A. R.; Green Polymerization Methods: Renewable Starting Materials, Catalysis and Waste Reduction; Wiley-VCH Verlag: Weinheim, Germany, 2011.

3. Welton, T.; Chem. Rev. 1999, 99, 431.

4. Lu, J.; Yan, F.; Texter, J.; Prog. Polym. Sci. 2009, 34, 431.

5. Gorke, J.; Srienc, F.; Kazlauskas, R.; Biotechnol. Bioprocess Eng. 2010, 15, 40.

6. Pham, T. P. T.; Cho, C. W.; Yun, Y.-S.; Water Res. 2010, 44, 352.

7. Farran, A.; Cai, C.; Sandoval, M.; Xu, Y.; Liu, J.; Hernaiz, M. J.; Linhardt, R. J.; Chem. Rev. 2015, 115, 6811.

8. Abbott, A.; Barron, J.; Ryder, K.; Wilson, D.; Chem. - Eur. J. 2007, 13, 6495.

9. Tang, B.; Row, K. H.; Monatsh. Chem. 2013, 144, 1427.

10. Zhang, Q.; Vigier, K. O.; Royer, S.; Jérôme, F.; Chem. Soc. Rev. 2012, 41, 7108.

11. Tang, B.; Zhang, H.; Row, K. H.; J. Sep. Sci. 2015, 38, 1053.

12. Carriazo, D.; Serrano, M. C.; Gutiérrez, M. C.; Ferrer, M. L.; del Monte, F.; Chem. Soc. Rev. 2012, 41, 4996.

13. del Monte, F.; Carriazo, D.; Serrano, M. C.; Gutiérrez, M. C.; Ferrer, M. L.; ChemSusChem 2014, 7, 999.

14. Choi, Y. H.; van Spronsen, J.; Dai, Y.; Verberne, M.; Hollmann, F.; Arends, I. W. C. E.; Witkamp, G.-J.; Verpoorte, R.; Plant Physiol. 2001, 156, 1701.

15. Dai, Y.; Spronsen, J.; Witkamp, G.-J.; Verpoorte, R.; Choi, Y. H.; Anal. Chim. Acta 2013, 766, 61.

16. Dai, Y.; Witkamp, G.-J.; Verpoorte, R.; Choi, Y. H.; Food Chem. 2015, 187, 14.

17. Longo Jr., L. S.; Craveiro, M. V.; J. Braz. Chem. Soc. 2018, 29 , 1999.

18. Tomé, L. I. N.; Baião, V.; da Silva, W.; Brett, C. M. A.; Appl. Mater. Today 2018, 10, 30.

19. Vanda, H.; Dai, Y.; Wilson, E. G.; Verpoorte, R.; Choi, Y. H.; C. R. Chim. 2018, 21, 628.

20. Liu, Y.; Friesen, J. B.; McAlpine, J. B.; Lankin, D. C.; Chen, S.-N.; Pauli, G. F.; J. Nat. Prod. 2018, 81, 679.

21. Mota-Morales, J. D.; Sanchez-Leija, R. J.; Carranza, A.; Pojman, J. A.; del Monte, F.; Luna-Barcenas, G.; Prog. Polym. Sci. 2018, 78, 139.
22. Juneidi, I.; Hayyan, M.; Hashim, M. A.; Process Biochem. 2018 , 66, 33.

23. Xu, P.; Zheng, G.-W.; Zong, M.-H.; Li, N.; Lou, W.-Y.; Bioresour. Bioprocess. 2017, 4, 34.

24. Loow, Y.-L.; New, E. K.; Yang, G. H.; Ang, L. Y.; Foo, L. Y. W.; Wu, T. Y.; Cellulose 2017, 24, 3591.

25. Nkuku, C. A.; LeSuer, R. J.; J. Phys. Chem. B 2007, 111, 13271.

26. Abbott, A. P.; El Ttaib, K.; Frisch, G.; Ryder, K. S.; Weston, D.; Phys. Chem. Chem. Phys. 2012, 14, 2443.

27. Bahadori, L.; Abdul Manan, N. S.; Chakrabarti, M. H.; Hashim, M. A.; Mjalli, F. S.; Al-Nashef, I. M.; Hussain, M. A.; Phys. Chem. Chem. Phys. 2013, 15, 1707.

28. Gomez, F. J. V.; Espino, M.; Fernandez, M. A.; Raba, J.; Silva, M. F.; Anal. Chim. Acta 2016, 936, 91.

29. Shahbaz, K.; Mjalli, F. S.; Hashim, M. A.; Al-Nashef, I. M.; J. Appl. Sci. 2010, 10, 3349.

30. Shahbaz, K.; Mjalli, F. S.; Hashim, M. A.; Energy Fuels 2011, $25,2671$.

31. Shahbaz, K.; Mjalli, F. S.; Hashim, M. A.; Sep. Sci. Technol. 2013, 48, 1184.

32. Hayyan, A.; Hashim, M. A.; Hayyan, M.; Mjalli, F. S.; AlNashef, I. M.; J. Cleaner Prod. 2014, 65, 246.

33. Durand, E.; Lecomte, J.; Villeneuve, P.; Eur. J. Lipid Sci. Technol. 2013, 115, 379.

34. Huang, Z.-L.; Wu, B.-P.; Wen, Q.; Yang, T.-X.; Yang, Z.; J. Chem. Technol. Biotechnol. 2014, 89, 1975.

35. Durand, E.; Lecomte, J.; Baréa, B.; Villeneuve, P.; Eur. J. Lipid. Sci. Technol. 2014, 116, 16.

36. Zeng, C.-X.; Qi, S.-J.; Xin, R.-P.; Yang, B.; Wang, Y.-H.; Bioprocess Biosyst. Eng. 2015, 38, 2053.

37. Leron, R. B.; Li, M.-H.; Thermochim. Acta 2013, 551, 14.

38. Sze, L. L.; Pandey, S.; Ravula, S.; Pandey, S.; Zhao, H.; Baker, G. A.; Baker, S. N.; ACS Sustainable Chem. Eng. 2014, 2 , 2117.

39. Garcia, G.; Atilhan, M.; Aparicio, S.; J. Phys. Chem. C 2015, 119, 21413.

40. Xia, S.; Baker, G. A.; Li, H.; Ravula, S.; Zhao, H.; RSC Adv. 2014, 4, 10586.

41. Vigier, K. D. O.; Chatel, G.; Jerome, F.; ChemCatChem 2015 , 7, 1250 .

42. Tang, B.; Park, H. E.; Row, K. H. J.; Chromatogr. Sci. 2014, 53,836 .

43. Wei, Z.; Qi, X.; Li, T.; Luo, M.; Wang, W.; Zu, Y.; Fu, Y.; Sep. Purif. Technol. 2015, 149, 237.

44. Li, J.; Han, Z.; Zou, Y.; Yu, B.; RSC Adv. 2015, 5, 93937.

45. Dai, Y.; Rozema, E.; Verpoorte, R.; Choi, Y. H.; J. Chromatogr. A 2016, 1434, 50.

46. Das, A. K.; Sharma, M.; Mondal, D.; Prasad, K.; Carbohydr. Polym. 2016, 136, 930.

47. Chen, J.; Liu, M.; Wang, Q.; Du, H.; Zhang, L.; Molecules 2016, $21,1383$. 
48. Huang, Y.; Feng, F.; Jiang, J.; Qiao, Y.; Wu, T.; Voglmeir, J.; Chen, Z.-G.; Food Chem. 2016, 221, 1400.

49. Mukesh, C.; Gupta, R.; Srivastava, D. N.; Nataraj, S. K.; Pasad, K.; RSC Adv. 2016, 6, 28586.

50. Bednarz, S.; Fluder, M.; Galica, M.; Bogdal, D.; Maciejaszek, I.; J. Appl. Polym. Sci. 2014, 131, 40608.

51. Mota-Morales, J. D.; Gutiérrez, M. C.; Sanchez, I. C.; LunaBárcenas, G.; del Monte, F.; Chem. Commun. 2011, 47, 5328.

52. Mota-Morales, J. D.; Gutiérrez, M. C.; Ferrer, M. L.; Sanchez, I. C.; Pojman, J.; del Monte, F.; Luna-Bárcenas, G.; J. Polym. Sci., Part A: Polym. Chem. 2013, 51, 1767.

53. Mota-Morales, J. D.; Gutiérrez, M. C.; Ferrer, M. L.; Jiménez, R.; Santiago, P.; Sanchez, I. C.; Terrones, M.; del Monte, F.; Luna-Bárcenas, G.; J. Mater. Chem. A 2013, 1, 3970.

54. Wang, J.; Han, J.; Khan, M. Y.; He, D.; Peng, H.; Chen, D.; Xie, X.; Xue, Z.; Polym. Chem. 2017, 8, 1616.

55. Tian, M.; Wang, J.; Zhou, J.; Han, J.; Du, F.; Xue, Z.; J. Polym. Sci., Part A: Polym. Chem. 2018, 56, 282.

56. Mendonça, P.; Lima, M. S.; Guliashvili, T.; Serra, A. C.; Coelho, J. F. J.; Polymer 2017, 132, 114.

57. Sánchez-Leija, R. J.; Torres-Lubián, J. R.; Reséndiz-Rubio, A.; Luna-Bárcenas, G.; Mota-Morales, J. D.; RSC Adv. 2016, 6, 13072.

58. Fernandes, P. M. V.; Campiña, J. M.; Pereira, N. M.; Pereira, C. M.; Silva, F.; J. Appl. Electrochem. 2012, 42, 997.

59. Park, T.-J.; Lee, S. H.; Green Chem. 2017, 19, 910.

60. Hosu, O.; Bârsan, M. M.; Cristea, C.; Săndulescu, R.; Brett, C. M. A.; Electrochim. Acta 2017, 232, 285.

61. Garcia-Arguelles, S.; Serrano, M. C.; Gutiérrez, M. C.; Ferrer, M. L.; Yuste, L.; Rojo, F.; del Monte, F.; Langmuir 2013, 29 , 9525.

62. Serrano, M. C.; Gutiérrez, M. C.; Jiménez, R.; Ferrer, M. L.; del Monte, F.; Chem. Commun. 2012, 48, 579.

63. Gómez-Patiño, M. B.; Gutiérrez-Salgado, D. Y.; GarcíaHernández, E.; Mendez-Mendez, J. V.; Andraca Adame, J. A.; Campos-Terán, J.; Arrieta-Baez, D.; Front. Mater. 2015, 2, article 67.

64. Linoletto, F.; Timo, A.; Frigione, M.; Thermochim. Acta 2015, 612,70 .
65. Maka, H.; Spychaj, T.; Adamus, J.; RSC Adv. 2015, 5, 82813.

66. Gutiérrez, M. C.; Rubio, F.; del Monte, F.; Chem. Mater. 2010 , 22,2711

67. Carriazo, D.; Gutiérrez, M. C.; Ferrer, M. L.; del Monte, F.; Chem. Mater. 2010, 22, 6146.

68. Carriazo, D.; Gutiérrez, M. C.; Pico, F.; Rojo, J. M.; Fierro, J. L. G.; Ferrer, M. L.; del Monte, F.; ChemSusChem 2012, 1405.

69. Chen, L.; Deng, J.; Hong, S.; Lian, H.; J. Sol-Gel Sci. Technol. 2018, 86, 795.

70. Cho, J. Y.; Choi, H.-M.; Oh, K. W.; Text. Res. J. 2016, 86, 1318.

71. Wang, Q.; Yao, X.; Geng, Y.; Zhou, Q.; Lu, X.; Zhang, S.; Green Chem. 2015, 17, 2473.

72. Bangde, P. S.; Jain, R.; Dandekar, P.; ACS Sustainable Chem. Eng. 2016, 4, 3552.

73. Yang, J.; Vigier, K. O.; Gu, Y.; Jérôme, F.; ChemSusChem 2015 , $8,269$.

74. Supeno, S.; Daik, R.; El-Sheikh, S. M.; BioResources 2014, 9 , 1267.

75. Mondal, D.; Sharma, M.; Wang, C.-H.; Lin, Y.-C.; Huang, H.C.; Saha, A.; Nataraj, S. K.; Prasad, K.; Green Chem. 2016, 18, 2819.

76. Sirviö, J. A.; Visanko, M.; Liimatainen, H.; Biomacromolecules 2015, 17, 3025.

77. Procentese, A.; Johnson, E.; Orr, V.; Garruto, C. A.; Wood, J. A.; Marzocchella, A.; Rehmann, L.; Bioresour. Technol. 2015, 192, 31.

78. Xu, G.-C.; Ding, J.-C.; Han, R.-Z.; Dong, J.-J.; Ni, Y.; Bioresour. Technol. 2016, 203, 364.

79. Gunny, A. A. N.; Arbain, D.; Nashef, E. M.; Jamal, P.; Bioresour. Technol. 2015, 181, 297.

80. Kumar, A. K.; Parikh, B. S.; Pravakar, M.; Environ. Sci. Pollut. Res. 2016, 23, 9265.

81. Gómez, A. V.; Biswas, A.; Tadini, C. C.; Vermillion, K.; Buttrum, M.; Cheng, H. N.; Adv. Food Sci. Technol. 2018, 2, 125.

Submitted: September 25, 2018

Published online: January 8, 2019 